All106 894342

PUBLICATIONS

National Institute of Standards and Technology

Technology Administration, U.S. Department of Commerce

NIST Technical Note 1532

\title{
Relative Permeability Measurements for Metal-Detector Research
}

Michael D. Janezic

James Baker-Jarvis 



\section{NIST Technical Note 1532}

\section{Relative Permeability Measurements For Metal-Detector Research}

Michael D. Janezic

James Baker-Jarvis

Radio-Frequency Technology Division

Electronics and Electrical Engineering Laboratory

National Institute of Standards and Technology

Boulder, CO 80305

April 2004

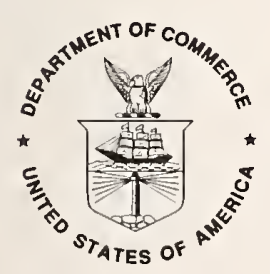

U.S. Department of Commerce

Donald L. Evans, Secretary

Technology Administration

Phillip J. Bond, Under Secretary for Technology

National Institute of Standards and Technology

Arden L. Bement, Jr., Director 
National Institute of Standards

and Technology

Technical Note 1532

Natl. Inst. Stand. Technol.

Tech. Note 1532

16 Pages (April 2004)

CODEN: NTNOEF
U.S. Government Printing Office

Washington: 2004
For sale by the Superintendent of Documents U.S. Government Printing Office Stop SSOP

Washington, DC 20402-0001

Phone: (202) 512-1800

Fax: (202) 512-2250

Internet: bookstore.gpo.gov 


\section{Contents}

1 Introduction 1

2 Overview and Definitions 2

3 Toroid Measurement Technique 4

3.0.1 Relative Permeability Model Excluding Toroid Conductivity . . . . 4

3.0.2 Relative Permittivity Model Including Toroid Conductivity . . . . . . 5

4 Measurements of Relative Permeability $\quad 7$

5 Conclusions $\quad 11$

6 References 12 



\title{
Relative Permeability Measurements for Metal-Detector Research
}

\author{
Michael D. Janezic and James Baker-Jarvis \\ Electromagnetics Division, National Institute of Standards and Technology, \\ Boulder, CO 80305
}

\begin{abstract}
We examine a measurement method for characterizing the low-frequency relative permeability of ferromagnetic metals commonly used in the manufacture of weapons. In addition to the metal's conductivity and geometry, the relative permeability is another important variable in the detection of metal weapons. We describe a measurement method for measuring the relative permeability of toroidal metal samples of rectangular cross section. Taking into account the finite conductivity of the metal and skin depth, we present a model for the inductance of a wound toroid from which the permeability is calculated. Relative permeabilities of ferritic and martensitic stainless steels are presented as a function of frequency and magnetic field strength.
\end{abstract}

Key words: conductivity; loss factor; magnetic response; metal detector; permeability.

\section{Introduction}

The purpose of this report is to disseminate information on the characterization of the relative permeability of ferromagnetic metals for use in metal-detector research. Hand-held (HH) and walk-through (WT) metal detectors sense a perturbation of the applied magnetic fields caused by the presence of metallic objects. In order to study the interaction of metal detectors with metals, reliable data are needed on the conductivity and permeability of metals used to test the detector. Previously, we have studied the measurement process for determining the metal conductivity [1]. Although most of the metals considered in Ref. [1] 


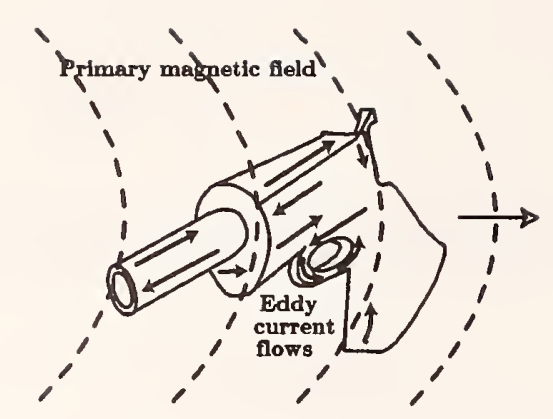

Figure 1: Approximate eddy currents on a handgun due to an incident variable magnetic field.

were nonmagnetic, there were several ferromagnetic metals with magnetic properties. Some magnetic property data exist for these materials [2]. However, for the low magnetic fields employed in metal-detection systems, the relative permeabilities of these materials are not well known as a function of frequency or applied magnetic field. The relative permeability is also a function of temperature. Although we did not attempt to perform temperaturedependent measurements, this aspect of the metal properties is summarized in Ref. [3]. This note describes a simple method for determining the relative permeability of ferromagnetic metals and presents measurement results for two ferromagnetic stainless steels commonly used in the manufacture of weapons.

The first section provides an overview and some definitions necessary for understanding the basic properties of ferromagnetic metals. The next section describes two theoretical models for a wound metal toroid from which we can calculate the relative permeability of the toroid specimen. The first model neglects the effects of the finite conductivity of the toroid and the skin-depth effect, while the second model takes these effects into account when determining the magnetic-field distribution in the toroid. In the final section we describe the measurement system and present relative permeabilities of ferromagnetic stainless steels as a function of frequency and applied magnetic field strength.

\section{Overview and Definitions}

Interactions of magnetic fields with materials in a metal detector are related to the relative permeability $\mu_{r}^{\prime}$, conductivity $\sigma$, and the size and shape of the object $[4,5]$. Time-varying magnetic fields in a metal detector interact with metallic objects by inducing eddy currents on the object's surface. The currents in the conductor are generated by the applied magnetic field as expressed by $\mathbf{J}=\nabla \times \mathbf{H}$. These eddy currents modify the incident magnetic field and thereby allow detection by receiving coils (see Figure 1). 


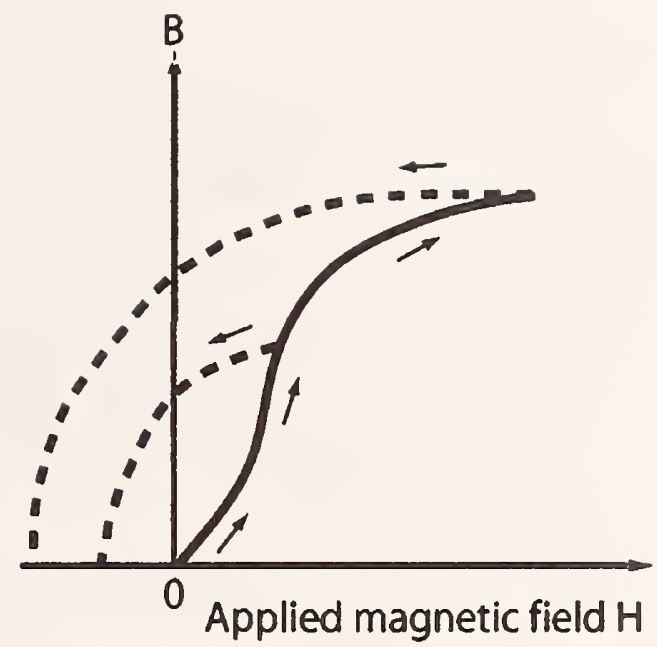

Figure 2: Magnetization curve for a ferromagnetic material.

One of the most important features of ferromagnetic metals, such as nickel, iron and cobalt, is their large magnetic moment. Since many stainless steel alloys include these materials, stainless steels can exhibit various levels of magnetic behavior.

A ferromagnetic metal in a demagnetized state is composed of many small magnetized domains. In this state, these domains are randomly oriented so that the averaged magnetic moment over the entire sample is zero. However, when a magnetic field is applied to the sample, the magnetic moment of each domain tries to align itself with the magnetic field. Figure 2 shows a B-H magnetization curve for a typical ferromagnetic metal, with the magnetic flux density $B$ plotted as a function of the applied magnetic field $H$.

For metal-detector systems, the applied magnetic field is small and near the origin of the magnetization curve. For this region, the magnetization effects are reversible and, if the applied field is static, no hysteresis effects exist. As a result, the relationship between $B$ and $H$ is linear, where $B=\mu_{0} \mu_{r}^{\prime} H$, with $\mu_{0}=4 \pi \times 10^{-7} \mathrm{H} / \mathrm{m}$ being the permeability of free space. The relative permeability $\mu_{r}^{\prime}$ in this region is also known as the initial permeability. A more in-depth description of ferromagnetic behavior can be found in Ref. [6].

The level of interactions of the applied magnetic field of a metal detector with a ferromagnetic metal depend on the relative permeability $\mu_{r}$, conductivity $\sigma$, and the size and shape of the metal object. Electromagnetic fields are attenuated as they travel through ferromagnetic metals. The depth of penetration at which the electromagnetic field decreases to $1 / e$ of its value at the surface is called the skin depth. The skin depth $\delta$ of a conducting metal is the depth at which a plane wave traveling through the conductor is decreased from 
its initial magnitude by a factor of $1 / e$ :

$$
\delta=\frac{1}{\sqrt{\pi f \mu_{0} \mu_{r}^{\prime} \sigma}},
$$

where $f$ is the frequency, $\sigma$ is the conductivity of the conductor, and $\mu_{r}^{\prime}$ is the relative permeability of the conductor. We see that the frequency, conductivity, and relative permeability of the material determine the skin depth. At higher values of frequency, relative permeability, or conductivity, the skin depth decreases, and the attenuation of the wave traveling through the materials increases [7].

\section{Toroid Measurement Technique}

The relative permeability of a metal at low frequencies and low magnetic field intensities can be calculated from the measured inductance of a wound toroidal sample of metal of rectangular cross section. A typical test specimen is shown in Figure 3. A toroid wound with $n$ turns of insulated copper wire is connected to an impedance bridge, and the inductance is measured as a function of frequency and current, which is related to the strength of the magnetic field generated within the toroid. In order to calculate the relative permeability, we examined two models that describe the relationship between the measured inductance and the relative permeability of the toroid. The first model does not include the effects of skin depth, whereas the second model does include skin depth.

\subsubsection{Relative Permeability Model Excluding Toroid Conductivity}

In the first model, we assume that a toroid of rectangular cross-section is wound uniformly with $n$ turns of wire as shown in Figure 3. Another necessary assumption is that the toroid's relative permeability is much greater than one, allowing us to assume that all the magnetic flux is confined to the toroid. Finally, for the low magnetic field intensities generated within the toroid by the current in the windings, we assume that the relative permeability is linear. For this first model, we neglect the conductivity $\sigma$ of the toroid, thereby neglecting the effect of skin depth.

From Ampere's law, the magnetic field within the toroid is

$$
H_{\phi}=\frac{n I}{2 \pi r}
$$

where $I$ is the current applied to the terminals of the toroid's windings. The inductance $L$ 


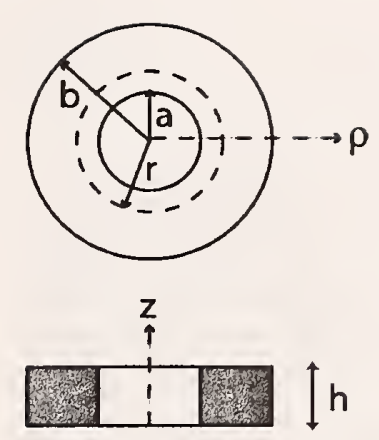

(a)

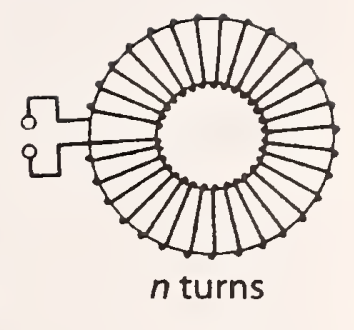

(b)

Figure 3: A typical toroid test specimen: (a) cross-section (b) toroid with windings.

of the toroid can be shown to be given by

$$
L=\frac{1}{I^{2}} \int_{V} \mathbf{B} \cdot \mathbf{H} d v=\frac{1}{I^{2}} \int_{a}^{b} \int_{0}^{2 \pi} \int_{0}^{h}\left(\mu_{0} \mu_{r} \frac{n I}{2 \pi \rho}\right)\left(\frac{n I}{2 \pi \rho}\right) \rho d \rho d \phi d z=\frac{\mu_{0} \mu_{r} n^{2} h}{2 \pi} \ln \frac{b}{a},
$$

where $n$ is the number of windings, $a$ is the inner diameter of the toroid, $b$ is the outer diameter of the toroid, $h$ is the thickness of the toroid, $\mu_{r}^{\prime}$ is the toroid's relative permeability, and $\mu_{0}$ is the relative permeability of free space. Solving for the relative permeability $\mu_{r}$ we obtain

$$
\mu_{r}^{\prime}=\frac{2 \pi L}{\mu_{0} n^{2} h \ln \frac{b}{a}}
$$

\subsubsection{Relative Permittivity Model Including Toroid Conductivity}

In the previous model, which neglected the toroid's conductivity, we obtained an expression for the magnetic field $H_{\phi}$ that did not include the effects of the metal's skin depth. However, due to the finite conductivity of the toroid, the effect of skin depth cannot be neglected, and an improved expression for the magnetic field must be found in order to accurately calculate the toroid's relative permeability. Namjoshi et al. [8] derived an expression for the magnetic field within a toroid of rectangular cross section, and his model is outlined briefly here.

When the conductivity $\sigma$ is included, the magnetic field $H_{\phi}$ within the toroid satisfies

$$
\frac{\partial^{2} H_{\phi}}{\partial \rho^{2}}+\frac{1}{\rho} \frac{\partial H_{\phi}}{\partial \rho}-\frac{H_{\phi}}{\rho^{2}}+\frac{\partial^{2} H_{\phi}}{\partial z^{2}}-k^{2} H_{\phi}=k^{2} H_{\phi 0}
$$

where

$$
k^{2}=j \omega \mu_{0} \mu_{r} \sigma
$$


and $H_{\phi 0}$ is the incident magnetic field. Using Ampere's law and assuming that the magnetic field is confined to the toroid, then $H_{\phi 0}$ is given by

$$
H_{\phi_{0}}=\frac{n I}{2 \pi \rho} .
$$

Given the value $H_{\phi 0}$ in (7), then (5) can be solved for $H_{\phi}$, where

$$
H_{\phi}=\frac{n I}{2 \pi \rho}+\sum_{s=1}^{\infty} \sum_{n=0}^{\infty} A_{n s} \cos \left(\frac{(2 n+1) \pi z}{h}\right)\left[\frac{J_{1}\left(\alpha_{s} \rho\right)}{J_{1}\left(\alpha_{s} b\right)}-\frac{Y_{1}\left(\alpha_{s} \rho\right)}{Y_{1}\left(\alpha_{s} b\right)}\right]
$$

and where $J_{1}$ and $Y_{1}$ are Bessel functions of the first and second kind of order one, $\alpha_{s}$ is the sth zero of

$$
J_{1}\left(\alpha_{s} a\right) Y_{1}\left(\alpha_{s} b\right)-J_{1}\left(\alpha_{s} b\right) Y_{1}\left(\alpha_{s} a\right)=0,
$$

and $A_{s n}$ are constants that are functions of the dimensions, conductivity, permeability of the toroid, and measurement frequency:

$$
A_{s n}=-\frac{2 k^{2} n I}{\pi} \frac{(-1)^{n}}{(2 n+1)} \frac{1}{\left[\frac{(2 n+1) \pi}{h}\right]^{2}+\alpha_{s}^{2}+k^{2}} \frac{\kappa(a-\kappa b)}{\left(1-\kappa^{2}\right) a b} J_{1}\left(\alpha_{s} a\right) Y_{1}\left(\alpha_{s} a\right),
$$

where

$$
\kappa=\frac{J_{1}\left(\alpha_{s} b\right)}{J_{1}\left(\alpha_{s} a\right)} .
$$

The first term for the magnetic field in (8) is identical to that found in (2), but the second term contains the effects of skin depth. The inductance of the toroid is then given by

$$
L=\frac{1}{I^{2}} \int_{V} \mathbf{B} \cdot \mathbf{H} d v=\frac{1}{I^{2}} \int_{a}^{b} \int_{0}^{2 \pi} \int_{0}^{h} \mu_{0} \mu_{r} H_{\phi}^{2} \rho d \rho d \phi d z,
$$

where $H_{\phi}$ is given in eq. (8). Solving for $\mu_{r}^{\prime}$ in (12), gives the relative permeability of the toroid. 


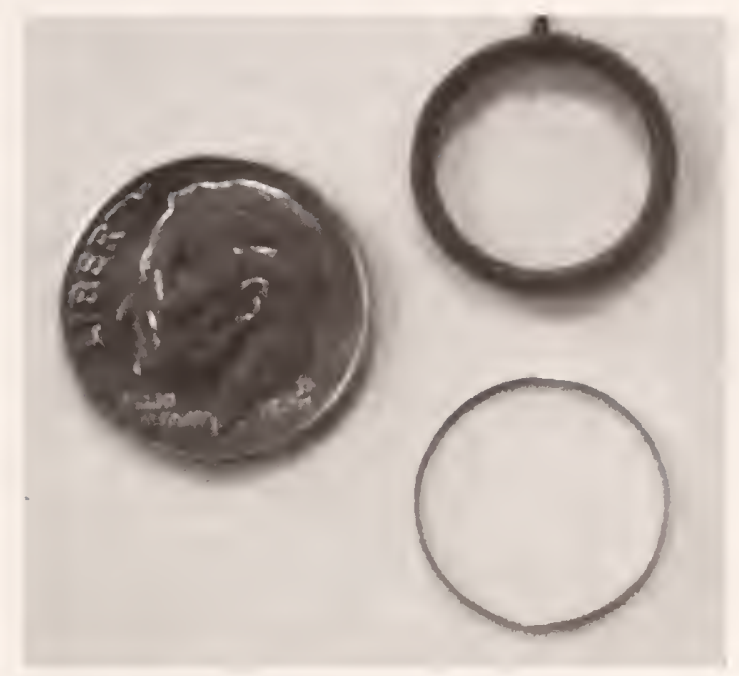

Figure 4: Stainless steel toroid samples with and without windings.

\section{Measurements of Relative Permeability}

We machined toroid samples, as shown in Figure 4, from two stainless steels. The first stainless material, UNS S43000, is a ferritic stainless steel, while the second material, UNS $\mathrm{S} 41600$, is a martensitic stainless steel. Both ferritic and martensitic steels are ferromagnetic and have a relative permeability greater than unity.

For all toroid samples, the outer diameter $2 a$ was $6.92 \mathrm{~mm}$, while the inner diameter $2 b$ was $6.54 \mathrm{~mm}$. The height $h$ of the toroid was $1.02 \mathrm{~mm}$. Each toroid was uniformly wound around the entire circumference with 106 turns of copper wire. The conductivity, from Ref. [1], of UNS 41600 was $1.53 \times 10^{6} \mathrm{~S} / \mathrm{m}$, while the conductivity of UNS 43000 was $1.77 \times 10^{6} \mathrm{~S} / \mathrm{m}$. In order to remove any residual magnetization, each toroid was demagnetized with an ac current source. Before each measurement, the toroid was connected to a current source, operating at $50 \mathrm{~Hz}$, and the current was slowly decreased from $1 \mathrm{~A}$ to $0.01 \mathrm{~mA}$.

After demagnetization, the toroid was connected to the terminals of an impedance bridge (precision LCR meter), and the inductance of the toroid was measured as a function of frequency and the current applied to the windings of the toroid. We varied the frequency from $500 \mathrm{~Hz}$ to $10 \mathrm{kHz}$, while the root-mean-squared (rms) current varied from 0.1 to 10 $\mathrm{mA}$. Figures 5 and 6 show the measured inductance as a function of frequency and applied current for stainless steels UNS S41600 and UNS S43000.

Using the theoretical model described in Section 3.0.2, we calculated the relative permeability for both the USN 43000 and USN 41600 stainless steels; these data are shown in 


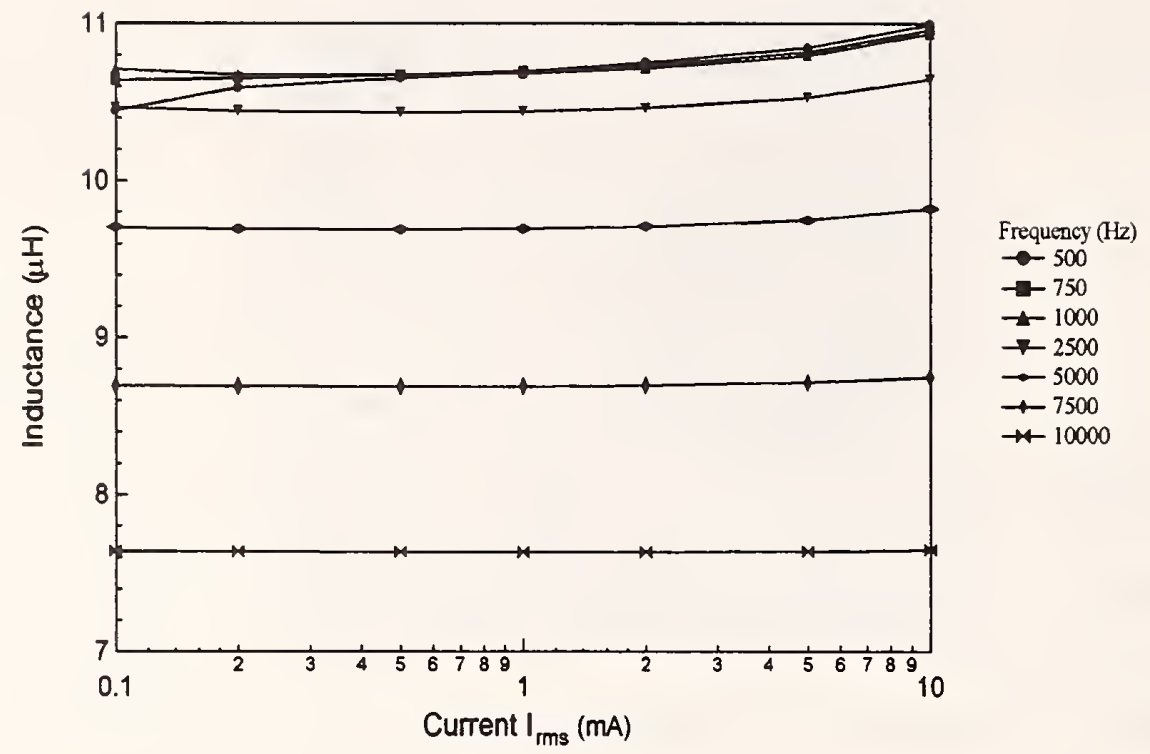

Figure 5: Measured inductance of a toroid of UNS S43000 stainless steel as a function of frequency and applied current.

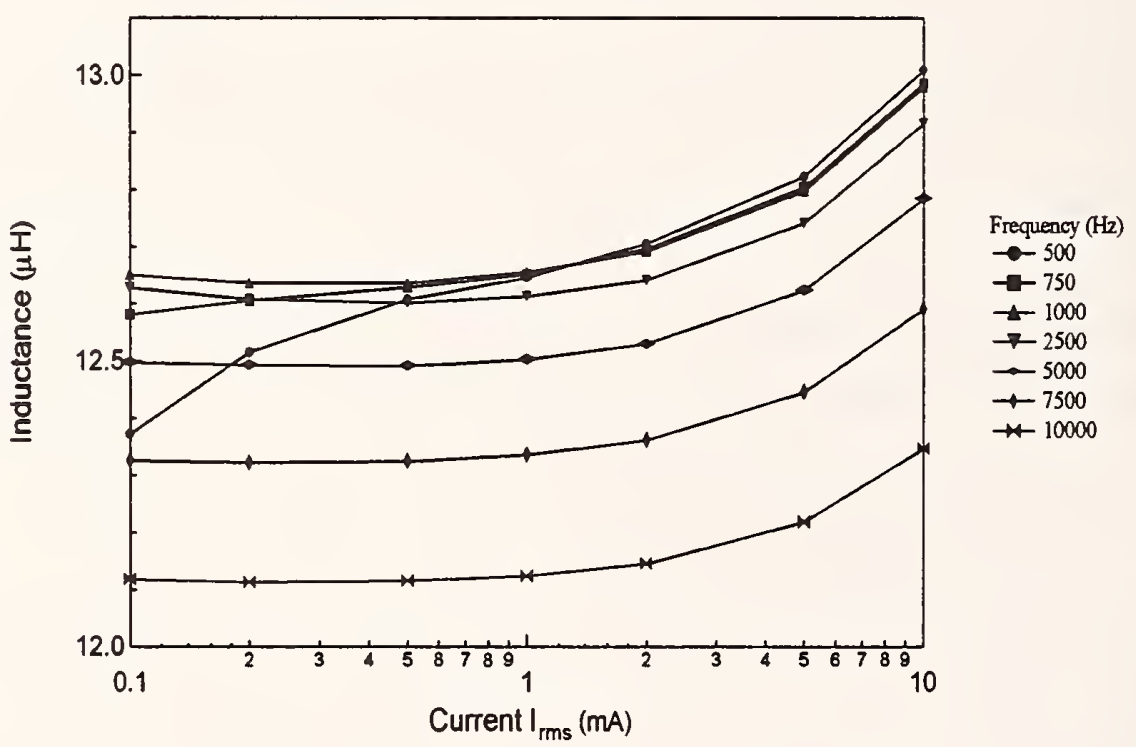

Figure 6: Measured inductance of a toroid of UNS S41600 stainless steel as a function of frequency and applied current.

Figures 7 and 8.

In addition to the plots of relative permeability, we plot the magnetic field density $B$ versus the applied magnetic field $H$ in Figures 9 and 10. As expected, due to the low applied magnetic field, each of the curves is linear. 


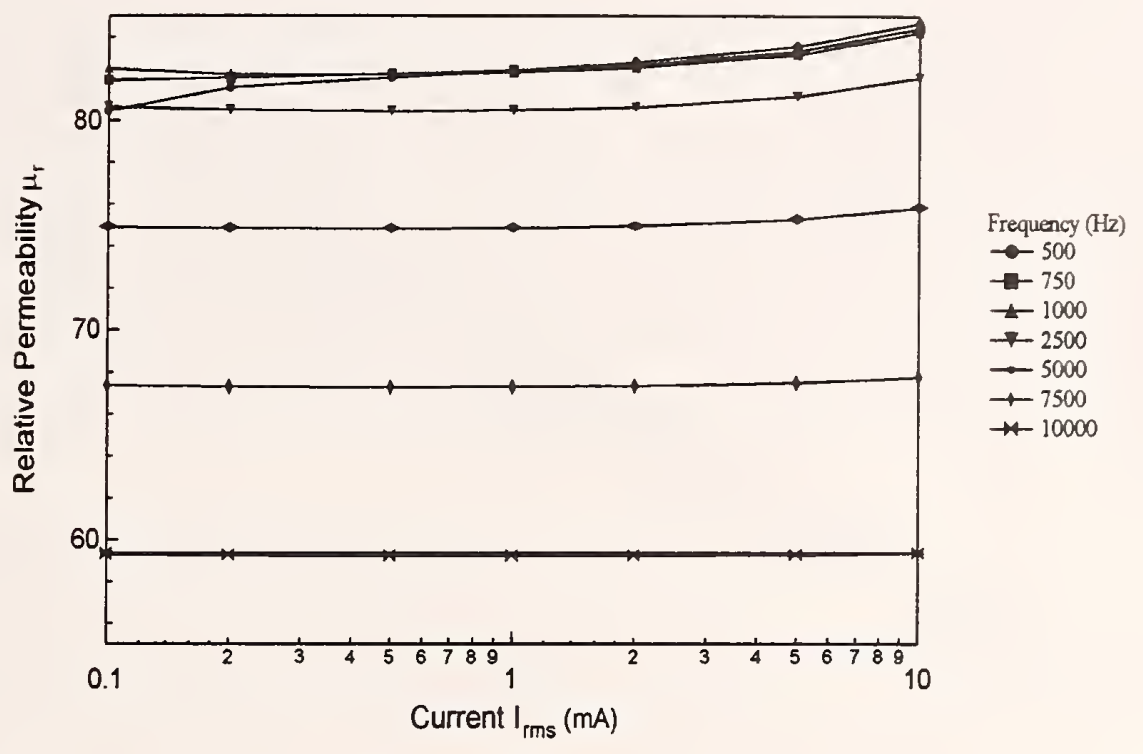

Figure 7: Relative permeability of UNS 43000 stainless steel.

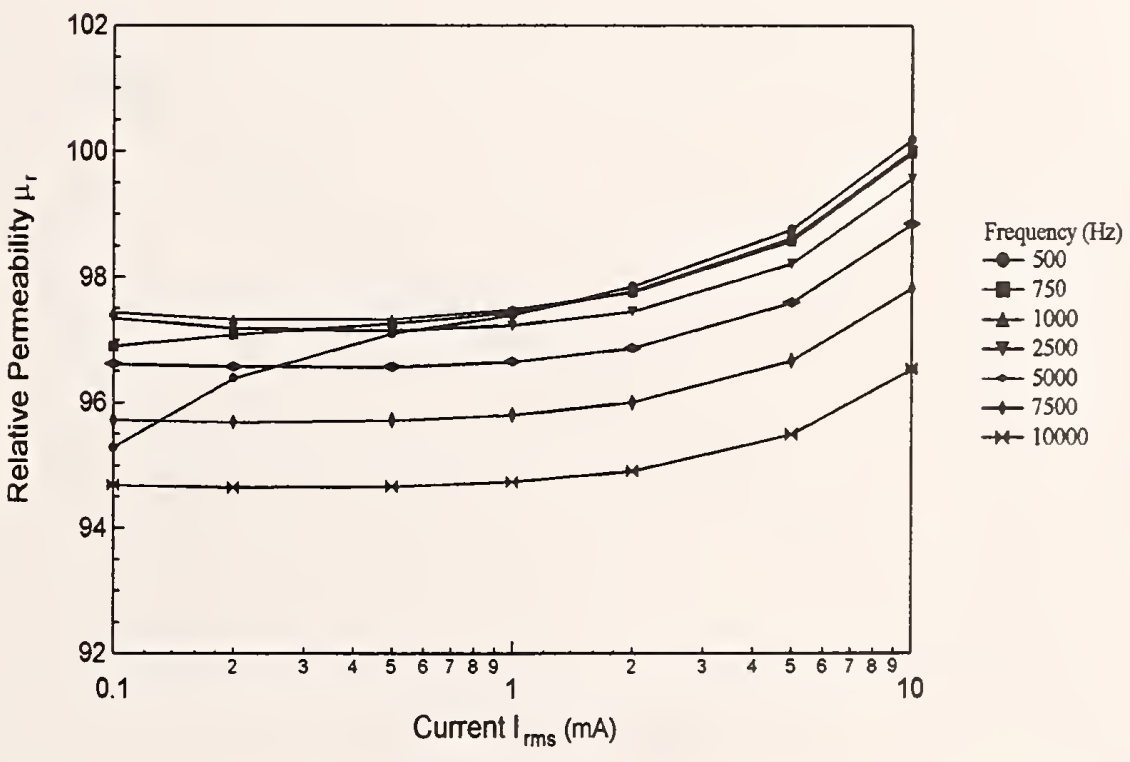

Figure 8: Relative permeability of UNS 41600 stainless steel. 


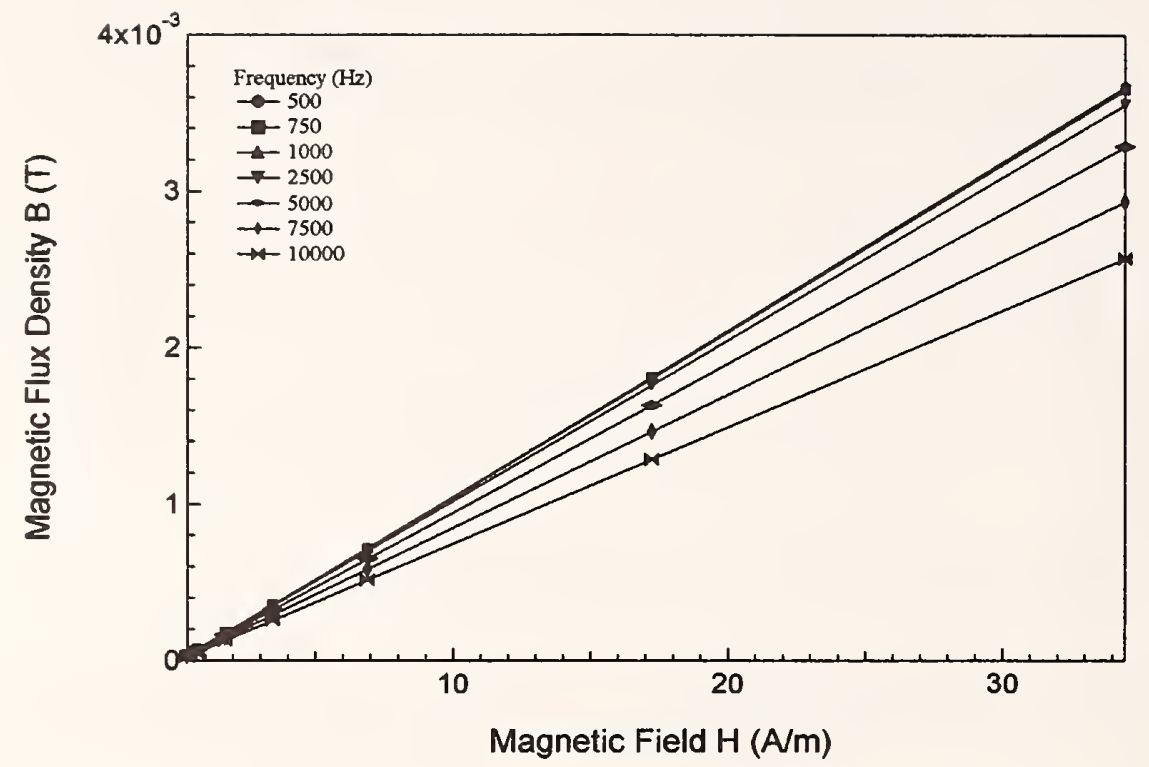

Figure 9: Magnetic flux density versus applied magnetic field for UNS 43000 stainless steel.

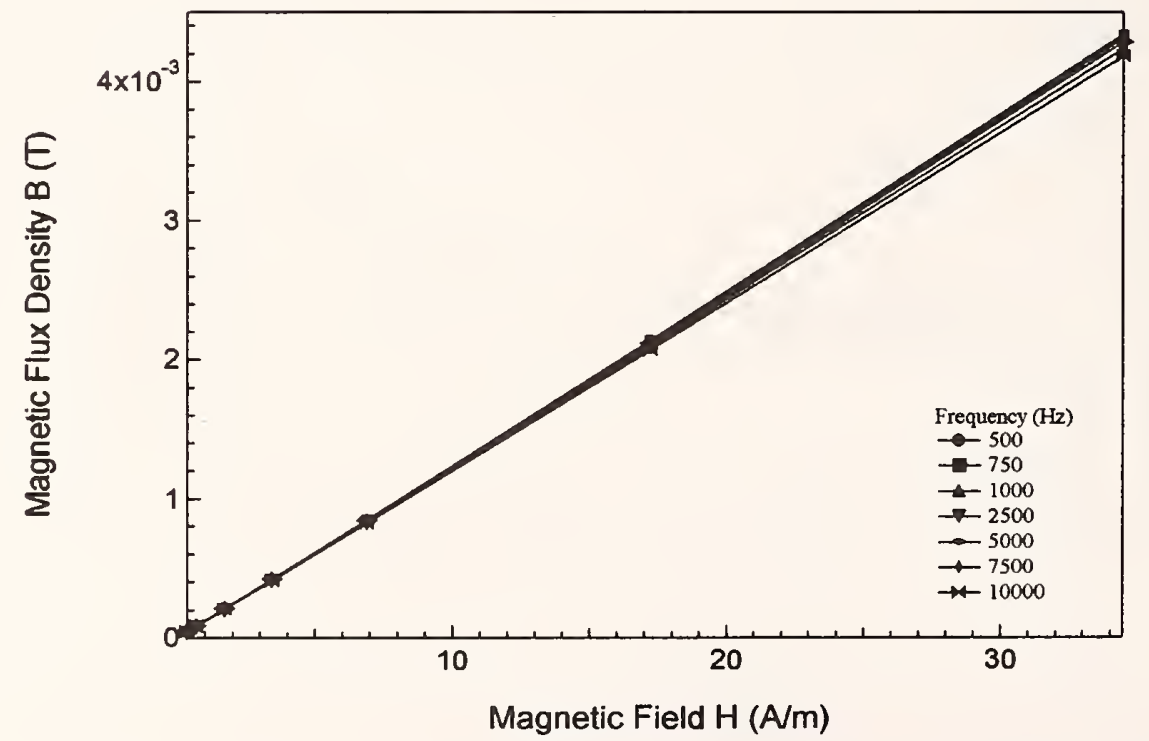

Figure 10: Magnetic flux density versus applied magnetic field for UNS 41600 stainless steel. 


\section{Conclusions}

We have described the procedure for measuring the relative permeabilities of metals at low frequencies and low applied magnetic fields. Using measurements of the inductance of a metal toroid of rectangular cross section, we calculated the relative permeability. A theoretical model for the inductance of a metal toroid of finite conductivity was reviewed. We presented measurements for the relative permeability of two stainless steels, UNS 41600 and 43000 , as a function of frequency and applied magnetic field strength and found that the toroid method, with the skin-depth correction model, works well for ferromagnetic metals.

\section{Acknowledgments}

Funding for this research was provided by the National Institute of Justice through the Office of Law Enforcement Standards at the National Institute of Standards and Technology. 


\section{References}

[1] M.D. Janezic, R.F. Kaiser, J. Baker-Jarvis, and G. Free, "Dc conductivity measurements of metals," NIST Technical Note 1531, National Institute of Standards and Technology, 2004.

[2] J.R. Davis, Ed., Metals Handbook, ASM International, Materials Park, OH, 1998.

[3] K. Ara, "Magnetic characteristics of ferromagnetic stainless steels," IEEE Trans. Magn., vol. 25, pp. 2617-2622, 1989.

[4] James Baker-Jarvis, Raian Kaiser, Michael D. Janezic, N. G. Paulter, and K. L. Stricklett, "Metal detector studies: Research materials," NIST Technical Note 1514, National Institute of Standards and Techology, 2002.

[5] Sadao Yarnazaki, Hiroshi Nakane, and Akio Tanaka, "Basic analysis of a metal detector," in IEEE Instrumentation and Measurement (Technology Conference), 2001, pp. 474-477.

[6] R.M. Bozorth, Ferromagnetism, IEEE Press, Piscataway, NJ, 1978.

[7] M. J. Peters, J. G. Stinstra, and M. Hendriks, "Estimation of the electrical conductivity of human tissue," Electromagn., vol. 21, pp. 545-557, 2001.

[8] K.V. Namjoshi, J. Douglas Lavers, and P.P. Biringer, "Eddy-current power loss in toroidal cores with rectangular cross section," IEEE Trans. Magn., vol. 34, pp. 636$641,1998$. 
Journal of Research of the National Institute of Standards and Technology-Reports NIST research and development in metrology and related fields of physical science, engineering, applied mathematics, statistics, biotechnology, and information technology. Papers cover a broad range of subjects, with major emphasis on measurement methodology and the basic technology underlying standardization. Also included from time to time are survey articles on topics closely related to the Institute's technical and scientific programs. Issued six times a year.

\section{Nonperiodicals}

Monographs-Major contributions to the technical literature on various subjects related to the Institute's scientific and technical activities.

Handbooks-Recommended codes of engineering and industrial practice (including safety codes) developed in cooperation with interested industries, professional organizations, and regulatory bodies.

Special Publications-Include proceedings of conferences sponsored by NIST, NIST annual reports, and other special publications appropriate to this grouping such as wall charts, pocket cards, and bibliographies.

National Standard Reference Data Series_-Provides quantitative data on the physical and chemical properties of materials, compiled from the world's literature and critically evaluated. Developed under a worldwide program coordinated by NIST under the authority of the National Standard Data Act (Public Law 90-396). NOTE: The Journal of Physical and Chemical Reference Data (JPCRD) is published bimonthly for NIST by the American Institute of Physics (AIP). Subscription orders and renewals are available from AIP, P.O. Box 503284, St. Louis, MO 63150-3284.

Building Science Series-Disseminates technical information developed at the Institute on building materials, components, systems, and whole structures. The series presents research results, test methods, and performance criteria related to the structural and environmental functions and the durability and safety characteristics of building elements and systems.

Technical Notes-Studies or reports which are complete in themselves but restrictive in their treatment of a subject. Analogous to monographs but not so comprehensive in scope or definitive in treatment of the subject area. Often serve as a vehicle for final reports of work performed at NIST under the sponsorship of other government agencies.

Voluntary Product Standards-Developed under procedures published by the Department of Commerce in Part 10, Title 15, of the Code of Federal Regulations. The standards establish nationally recognized requirements for products, and provide all concerned interests with a basis for common understanding of the characteristics of the products. NIST administers this program in support of the efforts of private-sector standardizing organizations.

Order the following NIST publications-FIPS and NISTIRs - from the National Technical Information Service, Springfield, VA 22161.

Federal Information Processing Standards Publications (FIPS PUB)-Publications in this series collectively constitute the Federal Information Processing Standards Register. The Register serves as the official source of information in the Federal Government regarding standards issued by NIST pursuant to the Federal Property and Administrative Services Act of 1949 as amended, Public Law 89-306 (79 Stat. 1127), and as implemented by Executive Order 11717 (38 FR 12315, dated May 11, 1973) and Part 6 of Title 15 CFR (Code of Federal Regulations).

NIST Interagency or Internal Reports (NISTIR)-The series includes interin or final reports on work performed by NIST for outside sponsors (both government and nongovernment). In gencral, initial distribution is handled by the sponsor; public distribution is handled by sales through the National Tcchnical Information Servicc, Springfield, VA 22161, in hard copy, electronic media, or microfiche form. NISTIR's may also report results of NIST projects of transitory or limitcd interest, including those that will be published subsequently in more comprehensive form. 
National Institute of Standards and Technology

Technology Administration

U.S. Department of Commerce

325 Broadway

Boulder, CO 80305 